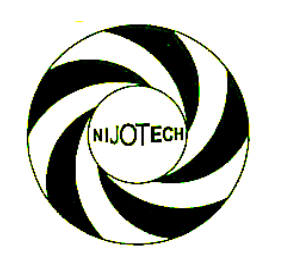

Nigerian Journal of Technology (NIJOTECH)

Vol. 37, No. 3, July 2018, pp. 633 - 639

Copyright@ Faculty of Engineering, University of Nigeria, Nsukka

Print ISSN: 0331-8443, Electronic ISSN: 2467-8821 www.nijotech.com

http://dx.doi.org/10.4314/njt.v37i3.11

\title{
PREDICTIVE MODEL FOR COMPRESSIVE STRENGTH OF CONCRETE MADE FROM RECYCLED CONCRETE COARSE AGGREGATES
}

\author{
A. W. Otunyo ${ }^{1, *}$ and B. G. Jephter ${ }^{2}$ \\ 1,2, Department of Civil Engineering, Rivers State UniV., NKPolu Port Harcourt, Rivers STATE, NiGERIA. \\ E-mail addresses: ${ }^{1}$ umutuigili@yahoo.com, ${ }^{2}$ jephterb@yahoo.com
}

\begin{abstract}
The objective of the study is to replace coarse natural aggregate with recycled concrete coarse aggregate (RCCA) for concrete production in order to determine the compressive strength of such concrete for different percentages of partial replacement using different water/cement ratios. Thereafter develop a predictive model for the compressive strength using different percentages of partial replacement and water/cement ratios. The polynomial regression model was applied to examine the correlation between the compressive strength of concrete, water cement ratio and $\% R C C A$. The following regression models were established for 28 days at 0.4, 0.45 and 0.50 water cement ratio, $f_{28,0.4}=-0.000(\% R C C A)^{2}-0.192(\% R C C A)+49.79$ with $R^{2}=1, f_{28,0.45}=0.000(\% R C A)^{2}-0.371(\% R C C A)+44.29$ with $R^{2}=1$, and $f_{28,0.50}=-0.001(\% R C C A)^{2}-0.386(\% R C C A)+41.91$ with $R^{2}=1$. At 28days test for water cement ratios of $0.55,0.6$ and 0.65 as $f_{28,0.55}=-0.0001(\% R C C A)^{2}-0.158(\% R C C A)+38.26$ with coefficient of determination of $R^{2}=1, f_{28,0.60}=0.010(\% R C C A)^{2}-0.1954(\% R C C A)+28.29$ with $R^{2}=1$, while for $W / C$ ratio of 0.65 is given as $f_{28,0.65}=-0.001(\% R C C A)^{2}+0.222(\% R C C A)+18.37$ with coefficient of determination, $R^{2}=1$. It was concluded that the increase or decrease in compressive strength of concrete was dependent on percentage replacement ratio of natural aggregate to recycled concrete aggregate (\%RCCA) and the amount of water to cement ratio $(\mathrm{w} / \mathrm{c})$ ratio of the mix. The significance of the study is that the compressive strength of concrete made with $R C C A$ which is a waste product can be predicted by using the predictive model developed.
\end{abstract}

Keywords: Concrete, Compressive strength, natural aggregate, Predictive model,Recycled concrete aggregate, Water/cement ratio.

\section{INTRODUCTION}

Recycled Concrete Aggregate (RCA) is the rubble obtained when structures made of concrete are demolished or renovated. They must be free of contaminants. They can be used as a partial replacement of natural aggregate in concrete production to help conserve the environment by decreasing amount of demolition waste which has to be disposed in landfills.

An experimental investigation on the early age behaviour of recycled aggregate concrete was carried out by [1]. In their research, the effect of recycled gravel and initial water saturation on plastics shrinkage and cracking was also investigated. It was established that initial water saturation of the RCA does not have any significance influence on plastic shrinkage of RAC. They observed that rate of substitution of recycled aggregate had no significance effects on the plastic shrinkages. They also concluded that the cracking sensitivity is not proportional to the recycled aggregate content.

A new method for predicting compressive strength of recycled aggregate concrete (RAC) mixtures was proposed by [2]; it considered some specific properties of the recycle concrete aggregate (RCA) such as; the high porosity and water absorption characteristics. The method also accounted for the effect of RCAs processing procedures, aggregate replacement ratio and initial moisture condition of aggregates. One uniqueness of the method is that, it considered the effective water to cement ratio which accounts for the free water transfer from RCAs in addition to effect of high porosity on the strength of RAC. The time evolution of compressive strength was determined from the attached mortar component of RCAs. However the proposed method is not applicable to the long term behaviour and other durability aspect of RAC.

The durability performance of concrete with recycled aggregate (RCA) from the construction and demolition 
waste from various locations in Portugal was also studied by [3]. They concluded that the use of recycled aggregate is detrimental to the quality of hardened concrete in terms of durability; in addition they also observed that carbonation resistance was the property with the worst results from the use of recycled aggregate in concrete.

The effect of recycled concrete aggregate (RCA) over some properties of concrete, composition and mix design influence on the concrete were investigated in mixes ranging from 0.45 to $0.6 \mathrm{w} / \mathrm{c}$ ratios, with $0 \%$, $20 \%, 50 \%$ and $100 \%$ coarse aggregates replacement by [4].

[5] studied the rheological behaviour of concrete made with fine recycled concrete aggregate. Two types of super plasticizers were investigated. It was observed that the incorporation of fine recycled concrete aggregate (FRCA) increases the shrinkage and Creep Deformation significantly. The incorporation of super plasticizers increases the Shrinkage at early ages and decreases the shrinkage at 91 days of age.

Recycled concrete aggregate (RCA) from two different sources in the production of concrete were investigated by [6]. The result revealed that both mechanical and durability terms were not significantly influenced by the aggregate sources. They observed that compressive strength of RAC decreases as the replacement ratio increases. Furthermore, the incorporation of RCA was responsible for increases of concrete's water absorption by immersion between $23 \%$ and $49 \%$, among to higher water absorption of the RCA.

This study was carried out to develop a predictive model for the compressive strength of concrete made for recycled concrete coarse aggregate (RCCA).

\section{MATERIALS AND METHODS}

\subsection{Materials}

The following materials were used for the experiment:

\subsubsection{Cement}

The cement that was used for sample production in this research is the Dangote 3X Portland Lime Stone Cement (PLC) of grade 42.5R. This cement is locally available in Nigeria in $50 \mathrm{~kg}$ bags. The cement was observed to conformed to [7]

\subsubsection{Fine Aggregate}

The fine aggregate was obtained from the Choba River in Emohua local government area of rivers state, Nigeria. The fine aggregate was observed to conform to [8]

\subsubsection{Recycled Concrete Coarse Aggregate}

The Recycled Concrete Coarse Aggregate was obtained from a demolished construction site at the main campus of the Rivers State University Port Harcourt. It was collected in bags and moved to the university laboratory.

\subsubsection{Coarse Aggregate}

Coarse aggregate used, was crushed angular and rough textured granite obtained from Crushed Rock Industry Nigeria Limited, Akamkpa in Cross River State, Nigeria. It is of maximum size of $20 \mathrm{~mm}$. It conformed to [8]

\subsubsection{Water}

The general portable water fit for drinking purposes was used in this research. The Water samples were obtained from the tap of the Civil Laboratory in Rivers State University Port Harcourt. The water used was tested and conformed to [9]

\subsection{Method}

\subsubsection{Crushing of the Recycled Concrete Aggregate}

The RCA used for this experiment were manually crushed with a harmer to obtain the aggregate size passing through the $20 \mathrm{~mm}$ sieve and retained on the $4.75 \mathrm{~mm}$ passing through the mechanical sieve.

\subsubsection{Concrete Batching}

The mix ratio used for the experiment was $1: 2: 4$ by weight with varying water cement ratios of $0.4,0.45$, $0.50,0.6$ and 0.65 . The Coarse aggregate (NA) was replaced with 15, 30, 4560 and 75\% RCA. For each replacement level, 3 specimens were prepared at compressive strengths where their average was obtained and used for analysis. Compressive strength at 28days was determined.

\subsubsection{Sieve Analysis}

The chippings were poorly graded Nominal single-sized aggregates of $20.0 \mathrm{~mm}-4.75 \mathrm{~mm}$ that grades outside the BS 882 Specifications Envelop Limits for coarse aggregates. The recycled concrete aggregate was found to be of Zone 2 envelop limit of BS 882 Specification.

\subsubsection{Specific Gravity}

Specific gravity values of (Gs) 2.70, 2.74, 2.79, and 3.045 was obtained for RCA, NA, River sand and cement respectively. Test on specific gravity was conducted in accordance with [11]

\subsubsection{Bulk Density and Unit weight}

Bulk Density and Unit Weight were performed in accordance with [11].

Vol. 37, No. 3, July 2018 
Predictive Model For Compressive Strength of ConCrete Made From RCCA， A.W. Otunyo \& B.G. Jephter

\subsubsection{Workability}

Slump test is used to ensure for concrete workability, this test was conducted in accordance with [12]

\subsubsection{Water Absorption Test}

This test was carried out in accordance with [13]

\section{RESULTS AND DISCUSSION}

3.1 Particle Size Distribution for Aggregate 3.1.1 Fine Aggregate

From Figure 1, the range of sieve size used was 150 um to $476 \mathrm{~mm}$.

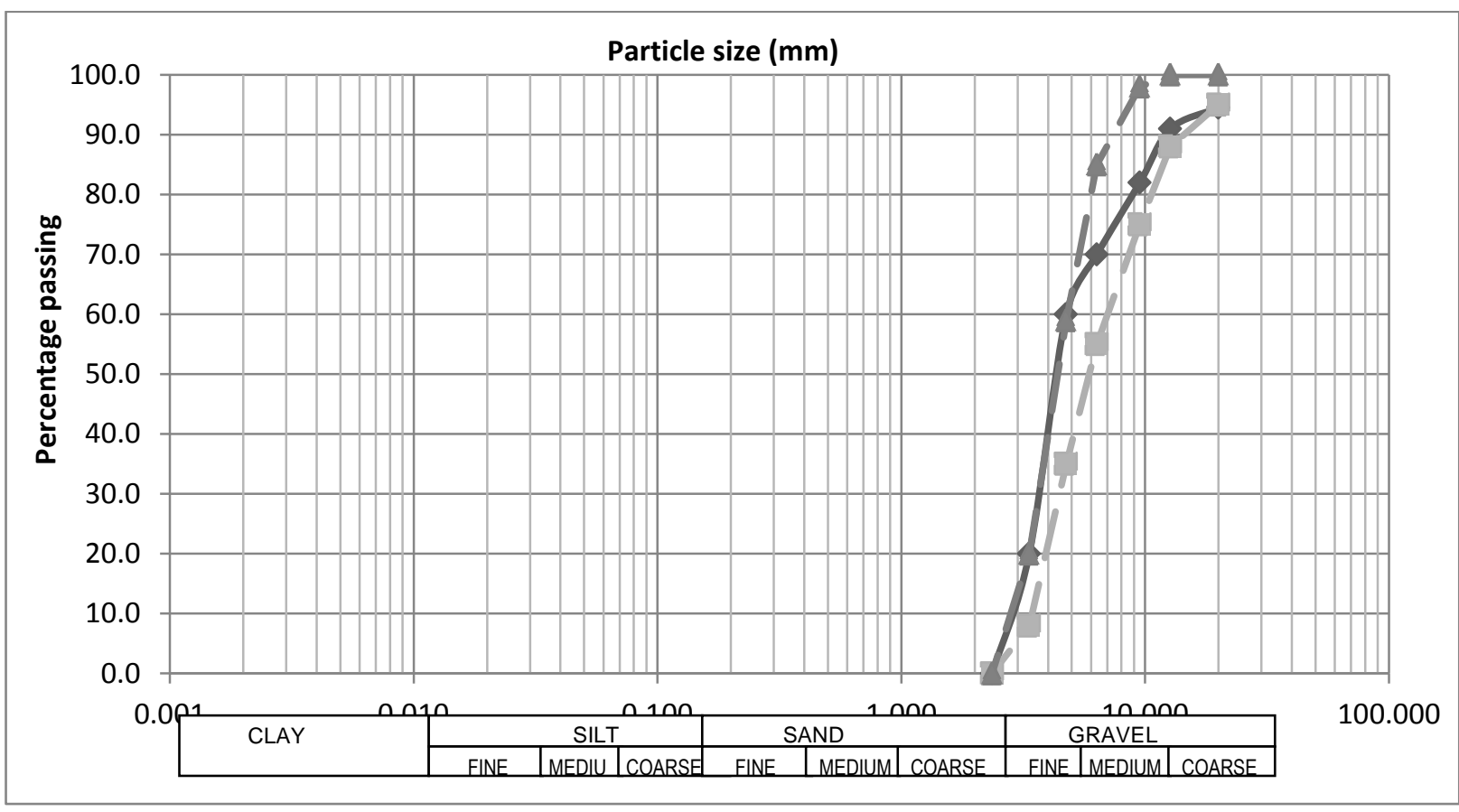

Figure 1: Grading Curves of Fine Aggregate

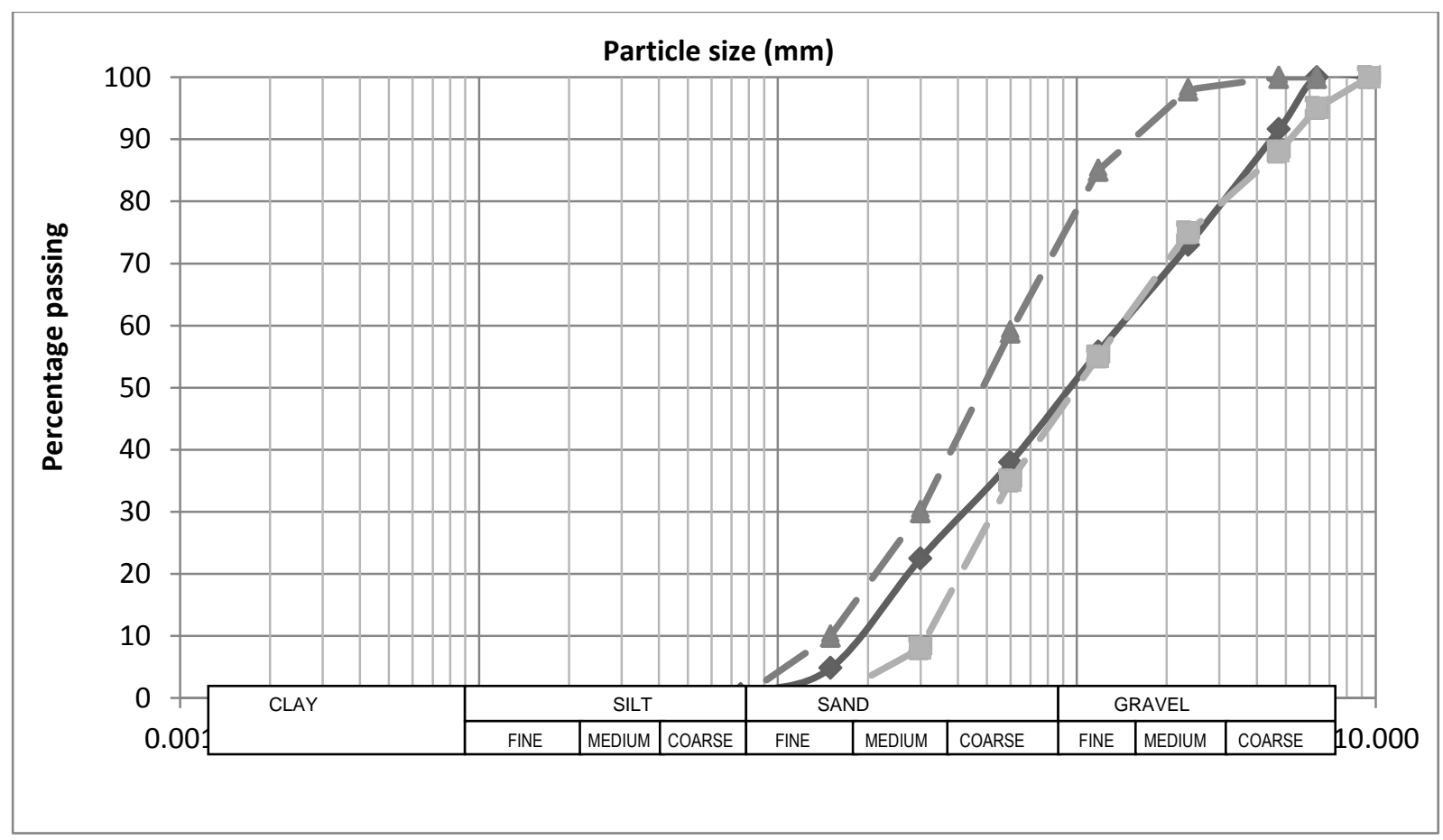

Figure 2: Grading Curves of Recycled Concrete Aggregate 


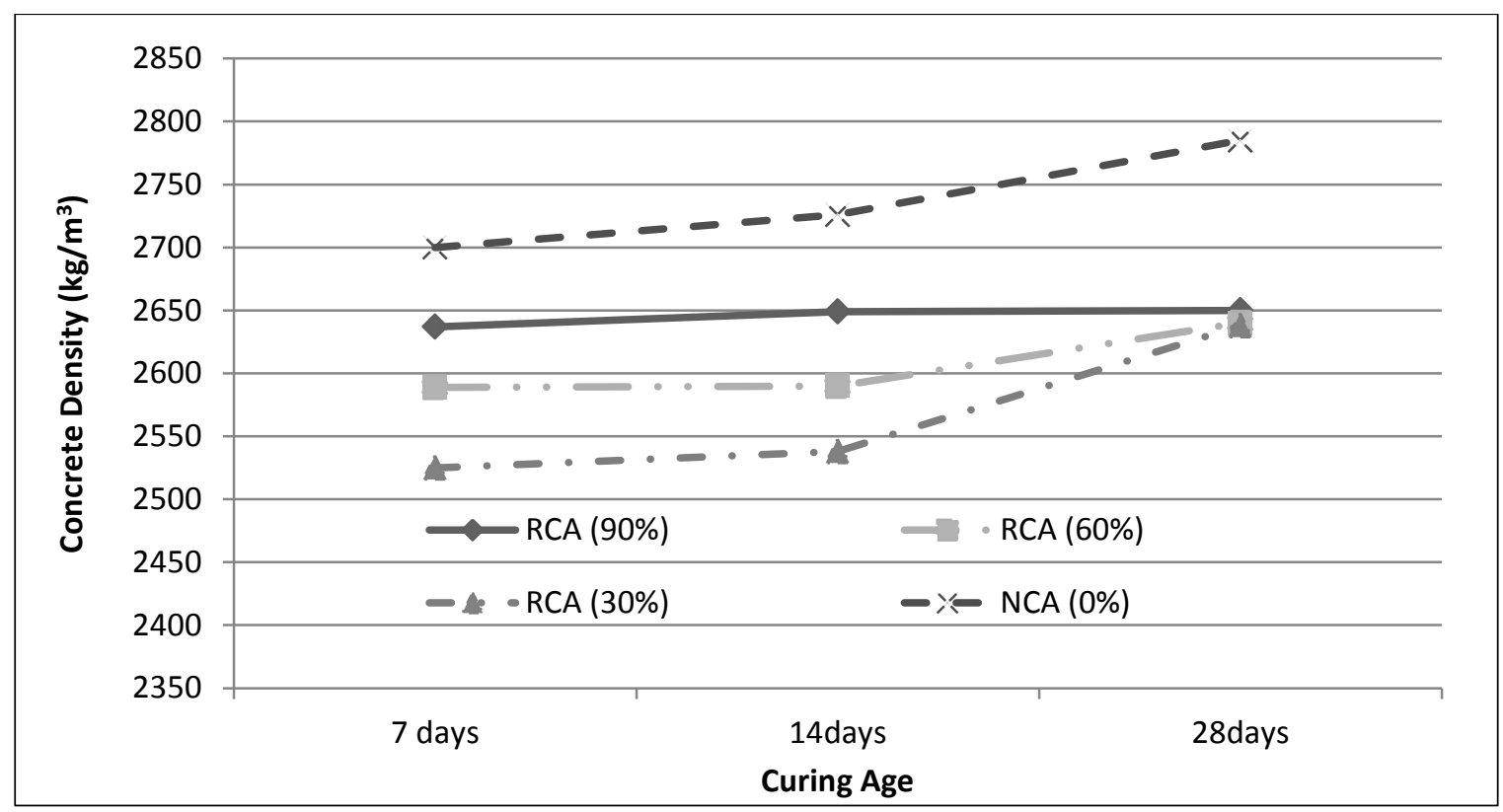

Figure 3: Concrete density versus Curing Age

\subsubsection{Recycled Concrete Aggregate}

It can be observed from Figure 2 that the recycled concrete aggregate was poorly grades nominal sized aggregates of $20.0 \mathrm{~mm}-4.75 \mathrm{~mm}$ that grades outside the BS 882 Specifications envelope

\subsection{Density of Concrete}

Figure 3 is the concrete density versus the curing age. The results show corresponding increase in density as the days of soaking is prolonged; this was different for concrete with reduced recycled aggregate inclusion. It can also be deduced from laboratory results that the pores in RCA caused the reduction in concrete weight. This may be attributed to the physical properties of
RCCA that contains concrete pieces and porous materials [14].

\subsection{Water Absorption}

Results presented in Figure 4 indicate that the water absorption rate increased with percentage replacement of RCA. Observed trend may be due to the presence of intermolecular pores in the concrete. The results also indicated an increase in mass of the concrete as the soaking days increased, resulting from linear increase in water absorption of the RCA modified concrete. The results above are similar to those observed by [15 and16].

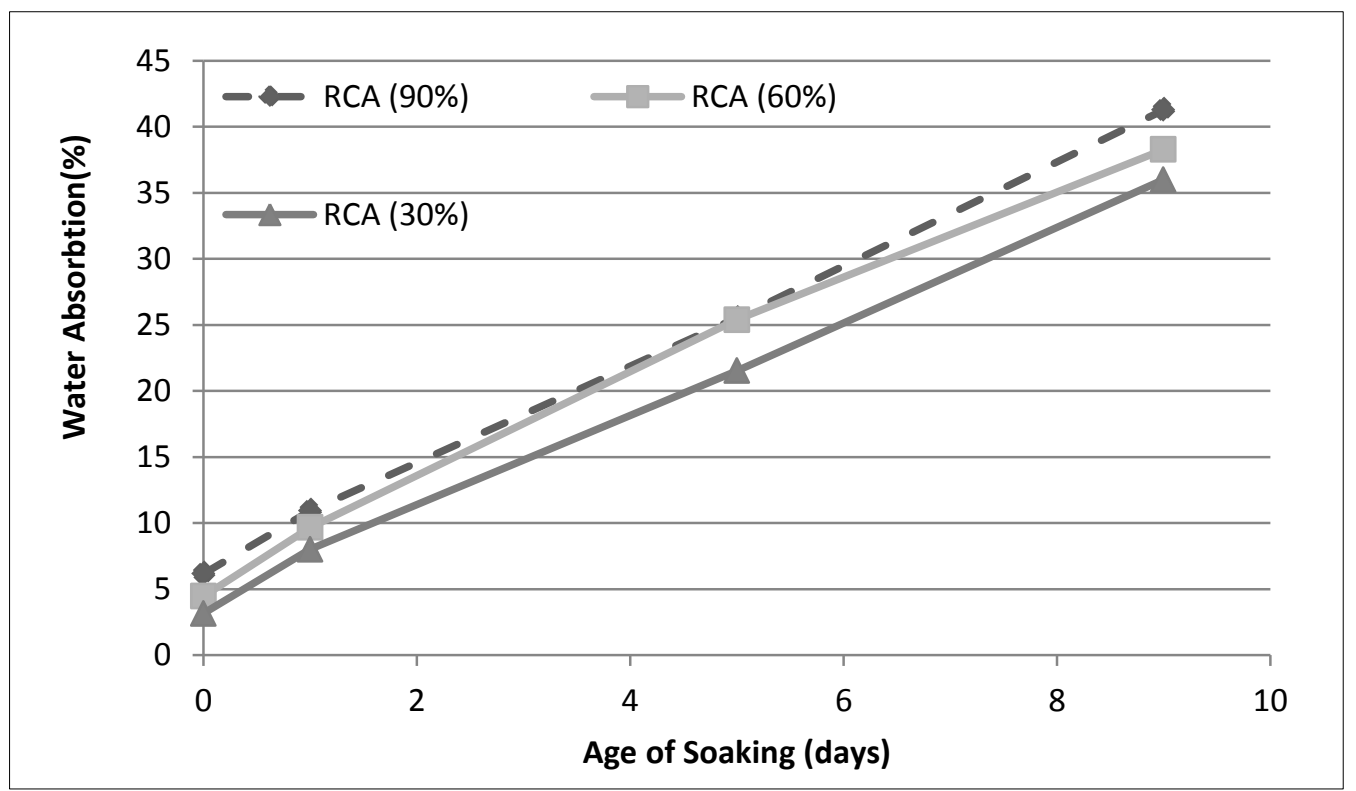

Figure 4: Relationship between Water Absorption (\%) and Age of Soaking 


\subsection{Compressive Strength}

The compressive strength of concrete depends on the water/cement ratio. The results in Tables 1 and 2 show the correlation between the compressive strength of an experimental and the predicted compressive strength of a partially replaced RCA concrete at varying water cement ratios of $0.4 .0 .45,0.5,0.55,0.60$, and 0.65 at 28days of curing. Results indicate an increase compressive strength as water cement ratio decreases and reduction in RCA replacement. The water cement ratio determines the porosity of the cement gel which further influences the strength of the concrete. These results are also similar to those obtained by [17] which reported decrease in in compressive strength up to $25 \%$ RCA.

\subsection{Regression Model to predict Concrete compressive strength}

The assessment of the relationship between compressive strength of recycled aggregate concrete partially replaced with natural aggregate varying water cement ratio was investigated in this research. The bond between the compressive strength of concrete, water cement ratio and \%RCA was considered using the concept of polynomial regression model, the equation of best fits and coefficients of determination was determined for concrete cured and crushed at 28days at $\mathrm{W} / \mathrm{C}$ ratio of $0.4,0.45$ and 0.50 shown in Figure 5 is as follows $f_{28,0.4}=-0.000(\% R C A)^{2}$ $0.192(\% \mathrm{RCA})+49.79$ with $\mathrm{R}^{2}=1, \mathrm{f}_{28,0.45}=$ $0.000(\% \mathrm{RCA})^{2}-0.371(\% \mathrm{RCA})+44.29$ with $\mathrm{R}^{2}=1$, and $\mathrm{f}_{28,0.50}=-0.001(\% \mathrm{RCA})^{2}-0.386(\% \mathrm{RCA})+41.91$ with $\mathrm{R}^{2}=1$ and concrete cured and crushed at 28days at $\mathrm{W} / \mathrm{C}$ ratio of $0.55,0.60$ and 0.65 shown in Figure 6 is as follows $\mathrm{f}_{28,0.55}=-0.0001(\% \mathrm{RCA})^{2}-0.158(\% \mathrm{RCA})+$ 38.26 with coefficient of determination of $\mathrm{R}^{2}=1$, $\mathrm{f}_{28,0.60}=0.010(\% \mathrm{RCA})^{2}-0.1954(\% \mathrm{RCA})+28.29$ with $\mathrm{R}^{2}=1$, while for $\mathrm{W} / \mathrm{C}$ ratio of 0.65 is given as $\mathrm{f}_{28,0.65}=-$ $0.001(\% \text { RCA })^{2}+0.222(\%$ RCA $)+18.37$ with coefficient of determination, $\mathrm{R}^{2}=1$. Results reveals that as percentage recycled concrete aggregate (\%RCA) and water cement $(\mathrm{w} / \mathrm{c})$ ratio was increased in the mixed proportion, the targeted compressive strength of concrete were been reduced

Table 1: Experimental and Predicted Compressive Strength for RCA Concrete for Varying Water Cement Ratios of $0.40,0.45$ and 0.50 .

\begin{tabular}{cccccccc}
\hline \multirow{2}{*}{ Age } & \multirow{2}{*}{ \%RCA } & \multicolumn{3}{c}{ Experimental Compressive Strength } & \multicolumn{3}{c}{ Predicted Compressive Strength } \\
\cline { 2 - 7 } & $0.40 \mathrm{~W} / \mathrm{C}$ & $0.45 \mathrm{~W} / \mathrm{C}$ & $0.50 \mathrm{~W} / \mathrm{C}$ & $0.40 \mathrm{~W} / \mathrm{C}$ & $0.45 \mathrm{~W} / \mathrm{C}$ & $0.50 \mathrm{~W} / \mathrm{C}$ \\
\hline \multirow{6}{*}{ 28Days } & 0 & 39.92 & 33.5 & 30.1 & 49.79 & 44.29 & 41.91 \\
& 15 & 38.50 & 31.34 & 30.52 & 46.91 & 38.725 & 36.12 \\
& 30 & 36.52 & 35.34 & 27.22 & 44.03 & 33.16 & 30.33 \\
& 45 & 33.01 & 25.09 & 24.00 & 41.15 & 27.595 & 24.54 \\
& 60 & 32.11 & 28.99 & 20.01 & 38.27 & 22.03 & 18.75 \\
& 75 & 28.74 & 15.86 & 15.11 & 35.39 & 16.465 & 12.96 \\
& 90 & 25.24 & 11.56 & 5.44 & 32.51 & 10.9 & 7.17 \\
\hline
\end{tabular}

Table 2: Experimental and Predicted Compressive Strength for RCA Concrete for Varying Water Cement Ratios of $0.55,0.60$ and 0.65

\begin{tabular}{cccccccc}
\hline \multirow{2}{*}{ Age } & \multirow{2}{*}{ \%RCA } & \multicolumn{3}{c}{ Experimental Compressive Strength } & \multicolumn{3}{c}{ Predicted Compressive Strength } \\
\cline { 4 - 8 } & $0.55 \mathrm{w} / \mathrm{c}$ & $0.60 \mathrm{w} / \mathrm{c}$ & $0.653 \mathrm{w} / \mathrm{c}$ & $0.55 \mathrm{w} / \mathrm{c}$ & $0.60 \mathrm{w} / \mathrm{c}$ & $0.65 \mathrm{w} / \mathrm{c}$ \\
\hline \multirow{3}{*}{ 28Day } & 0 & 27.86 & 24.30 & 21.91 & 38.26 & 28.29 & 24.37 \\
& 15 & 27.98 & 25.01 & 21.57 & 35.89 & 25.36 & 21.04 \\
& 30 & 23.31 & 21.98 & 18.97 & 33.52 & 22.43 & 17.71 \\
& 45 & 21.91 & 18.37 & 17.33 & 31.15 & 19.50 & 14.38 \\
& 60 & 18.91 & 16.74 & 15.99 & 28.78 & 16.57 & 11.05 \\
& 75 & 14.00 & 12.40 & 10.81 & 26.41 & 13.64 & 7.72 \\
\end{tabular}




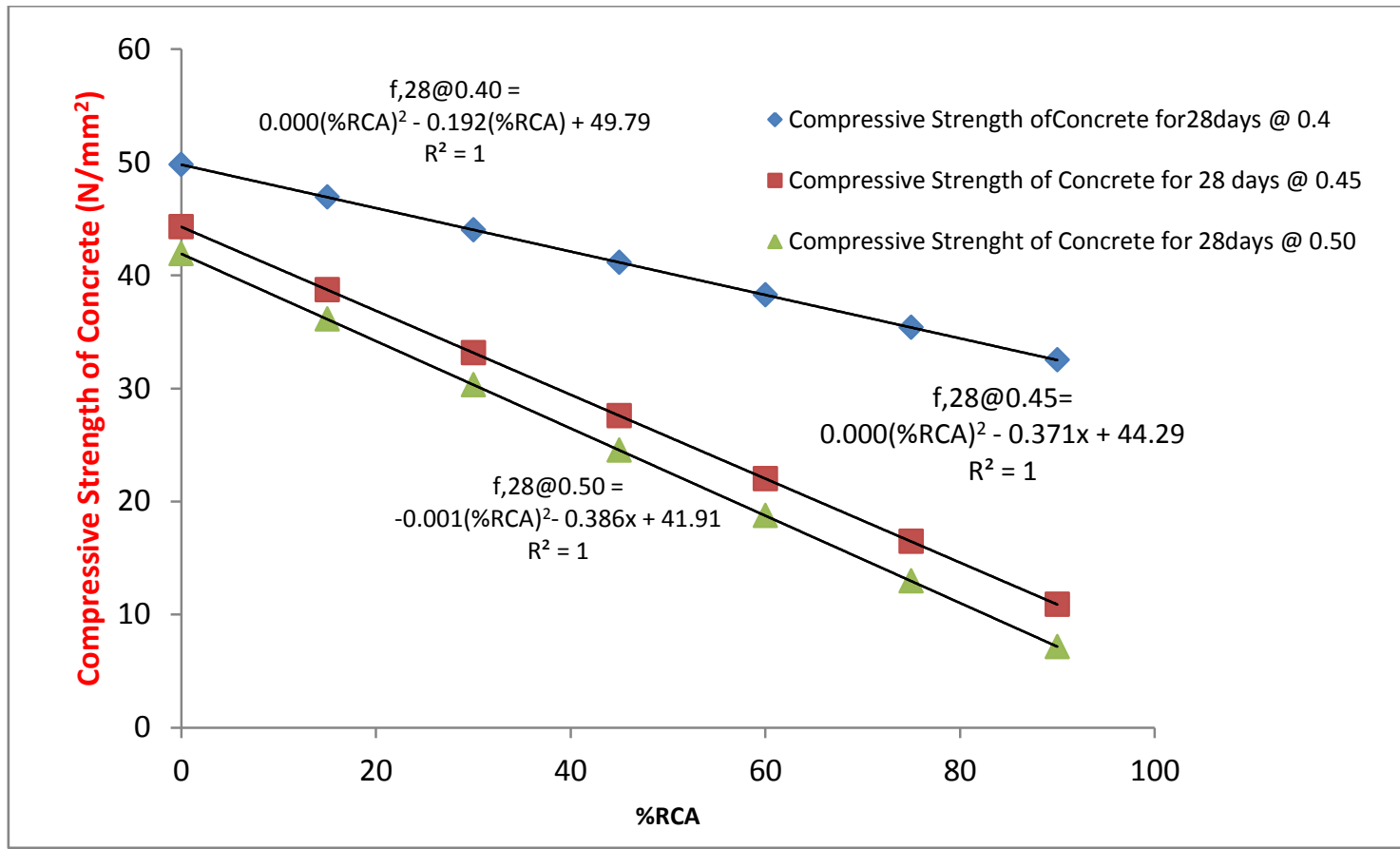

Figure 5: 28 days Compressive Strength and RCA content Relation for Recycled Concrete Aggregate for water/cement ratios of $0.4,0.45$ and 0.50 .

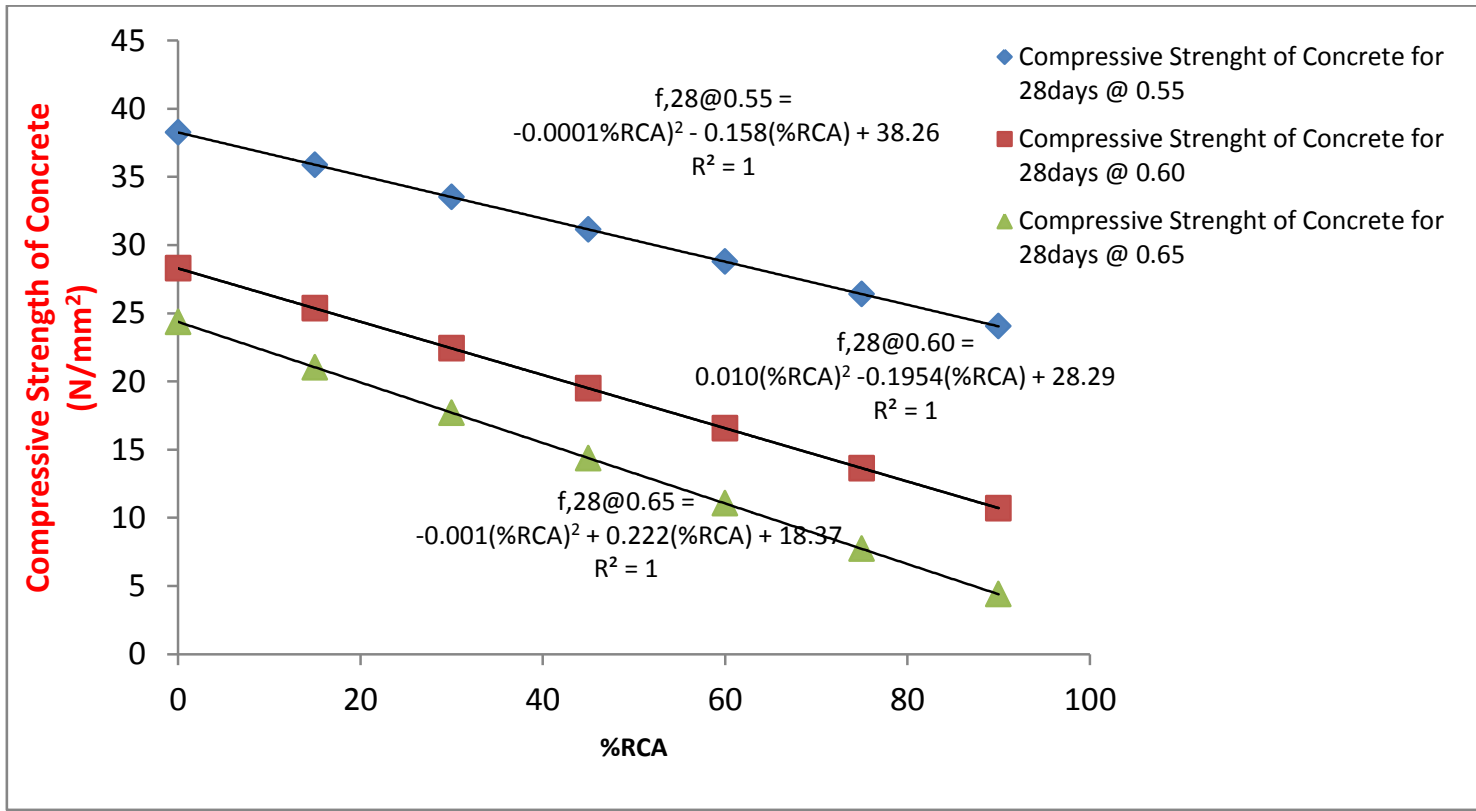

Figure 6: 28 days Compressive Strength and RCA content Relation for Recycled Concrete Aggregate for water/cement ratios of $0.55,0.60$ and 0.65 .

\section{CONCLUSION}

The following conclusions were drawn from study:

i. Results established a correlation between compressive strength of concrete, \%RCA and water cement ratio using polynomial regression model and equation of best fits for concrete cured and crushed for 28 days.

ii. Variation in compressive strength were influenced by percentage replacement ratios of natural aggregate to recycled aggregate and water cement $(\mathrm{w} / \mathrm{c})$ ratio.

iii. The developed predictive model is considered useful in simulating compressive strength of concrete produced using recycled concrete aggregates as partial replacement.

\section{REFERENCES}

[1] Ahmed, Z. B., Emmanuel, R. and Ahmed, L. (2016). Plastic shrinkage and cracking risk of recycled 
aggregate. Construction and Building Materials $121,733-745$.

[2] Pepe, M., Filho, R.D.T, Eduardus, A. B. K. and Martinelli, E. (2016). A novel mix design methodology for recycled aggregate concrete. Construction and Building Materials vol.122 pp 362-372.

[3] Miguel B., de Brito, J., Jorge, P.and Luís, E. (2015). Durability performance of concrete with recycled aggregate concrete. Construction and Building Materials vol.111 pp 342-362.

[4] Caijun, S., Yake, L., Jiake, Z., Wengui, L., Linlin C.,and Zhaobin, X..(2016).Performance enhancement of recycled concrete aggregate. A Review Journal of Cleaner Production.112. Pp. 466-472.

[5] Cartuxo F., de Brito, J., Evangelista, L., Jimenez J.RJ. and Ledesima, E.F. Rheological behaviour of concrete made with fine recycled concrete aggregates. Construction and Building Materials. Vol. 89 pp 36-47. (2015)

[6] Pedro, D., de Brito, J. and Evangelista, L. (2012) Influence of the use of recycled concrete aggregates from different sources on structural concrete. Construction and Building Materials Vol. 71,pp141151

[7] BS EN 196.1 (2016). Methods of testing cement. Determination of strength. British Standards Institute, London, United Kingdom.

[8] BS 882 (1992). Specification for aggregates from natural sources for concrete. British Standards Institute, London, United Kingdom.

[9] BS 3148 (1980). Methods of test for water for making concrete (including notes on the suitability of the water). British Standards Institute, London, United Kingdom.
[10] BS 812-103.1 (1985). Testing aggregates. Method for determination of particle size distribution. Sieve tests. British Standards Institute, London, United Kingdom.

[11] BS 812-2 (1995). Testing aggregates. Methods of determination of density. British Standards Institute, London, United Kingdom.

[12] BS EN 12350-8 (2010). Testing of fresh concrete. Self-compacting concrete. Slump flow test.

British Standards Institute, London, United Kingdom.

[13] BS 1881-122 (2011). Testing concrete. Method for determination of water absorption. British Standards Institute, London, United Kingdom

[14] Faisal, S. K., Nurul, B. A., Khairul, A. S. M. S. and Puteri, N. (2017). Mechanical properties of concrete containing recycled concrete aggregate (RCA) and ceramic waste coarse aggregate replacement. American Institute of Physics Conference Proceeding. Vol. 1891. No. 1 pp 1-7.

[15] Olorunsogo, F. T. (1999). Early age properties of recycled aggregate concrete. Proceedings of the International Seminar on exploiting water and concrete. University of Dundee, Scotland, United Kingdom, pp. 163-170.

[16] Poon, C. S., Shui, A. H., Lam, L., Fok, H. and Kou, S.C. (2004). Influence of moisture states of natural and recycled aggregates on the slump and compressive strength of concrete. Cement and Concrete Research. Vol., 34, No. 1, pp. 31-36.

[17] Mirjana, M., Vlastimir, R. and Sneezana, M. (2010). Recycled concrete as aggregate for structural concrete production. Sustainability. Vol. 2, pp. 1204-1225. 